\title{
Randomized placebo control study of insulin sensitizers (Metformin and Pioglitazone) in psoriasis patients with metabolic syndrome (Topical Treatment Cohort)
}

Surjit Singh ${ }^{1 *}$ and Anil Bhansali ${ }^{2}$

\begin{abstract}
Background: Increased prevalence of metabolic syndrome (MS) is observed in psoriasis. Metformin has shown improvement in cardiovascular risk factors while pioglitazone demonstrated anti proliferative, anti-inflammatory and anti angiogenic effects. Study objective is to evaluate the efficacy and safety of Insulin sensitizers (metformin and pioglitazone) in psoriasis patients with metabolic syndrome (MS).

Methods: Single centre, parallel group, randomized, study of metformin, pioglitazone and placebo in psoriasis patients with MS.

Results: Statistically significant improvement was observed in Psoriasis Area and Severity Index (PASI), Erythema, Scaling and Induration (ESI) and Physician global assessment (PGA) scores in pioglitazone ( $p$ values - PASI $=0.001$, $E S I=0.002, P G A=0.008$ ) and metformin groups ( $p$ values $-\mathrm{PASI}=0.001, E S I=0.016, P G A=0.012$ ) as compared to placebo. There was statistically significant difference in percentage of patients achieving $75 \%$ reduction in PASI and ESI scores in metformin ( $p$ value $-\mathrm{PASI}=0.001, \mathrm{ESI}=0.001$ ) and pioglitazone groups ( $p$ vaue $-\mathrm{PASI}=0.001, \mathrm{ESI}=0$. 001). Significant improvement was observed in fasting plasma glucose (FPG) and triglycerides levels in metformin and pioglitazone arms. Significant improvement was noted in weight, BMI, waist circumference, FPG, triglycerides and total cholesterol after 12 weeks of treatment with metformin while pioglitazone showed improvement in FPG, triglyceride levels, systolic blood pressure (SBP), diastolic blood pressure (DBP), total cholesterol and LDL cholesterol levels. There was no difference in pattern of adverse drug reaction in three groups.
\end{abstract}

Conclusion: Insulin sensitizers have shown improvement in the parameters of MS as well as disease severity in psoriasis patients.

Trial registration: CTRI Registration Number: CTRI/2011/12/002252. Registered on 19/12/2011.

Keywords: Psoriasis, Metabolic syndrome, Insulin sensitizers, Metformin, Pioglitazone

Abbreviations: ACE inhibitors, Angiotensin Converting Enzyme Inhibitors; ALT, Alanine Transaminase; AMPK, Adenosine Monophosphate-activated Protein Kinase; ANOVA, Analysis of Variance; AST, Aspartate Transaminase; BMI, Body Mass Index; CVS, Cardiovascular; DBP, Diastolic Blood Pressure; DM, Diabetes Mellitus; ERK1/ (Continued on next page)

\footnotetext{
*Correspondence: sehmby_ss@yahoo.com; ss.sehmby@gmail.com

'Department of Pharmacology, All India Institute of Medical Sciences (AllMS),

Jodhpur 342005, India

Full list of author information is available at the end of the article
} 


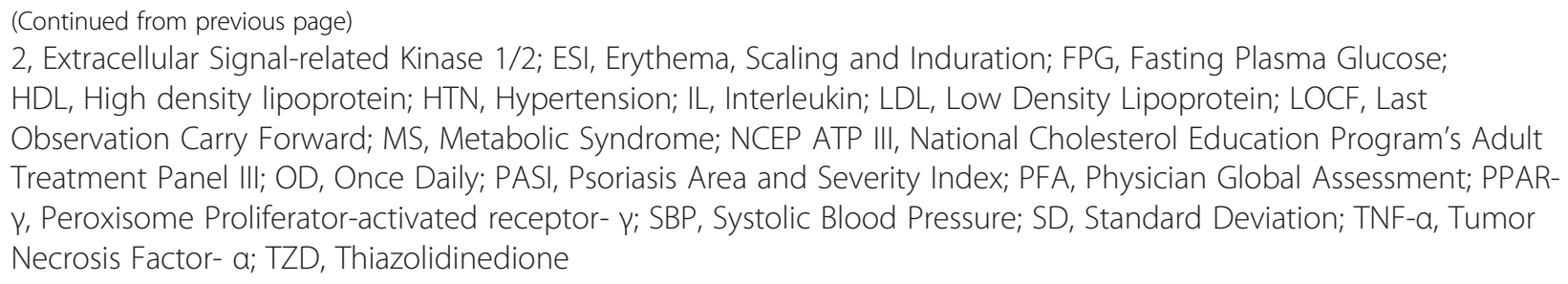

\section{Background}

Psoriasis is a chronic, inflammatory multisystemic disorder with genetic basis affecting 2-3\% of world population and affecting about $0.4 \%$ of Asians [1]. Psoriasis has been found to be associated more commonly with obesity, metabolic syndrome (MS) [1, 2], diabetes mellitus [3] and increased cardiovascular (CVS) mortality and morbidity [4-6]. Metabolic syndrome (MS) is a cluster of risk factors including central obesity, atherogenic dyslipidemia, hypertension and glucose intolerance and is a strong predictor of cardiovascular diseases, diabetes and stroke [7-9]. Many cytokines (e.g. interferon- $\gamma$, TNF- $\alpha$, IL-6, IL-8, IL-12, IL-17, IL-19 and IL-23) involved in the pathogenesis of psoriasis are also known to contribute to the cascade of metabolic syndrome such as hypertension, dyslipidemia and insulin resistance [10]. Prodifferentiating, antiproliferative, anti-inflammatory and antiangiogenic effects of Peroxisome proliferatoractivated receptor- $\gamma$ (PPAR- $\gamma$ ) ligands may potentially have beneficial role in psoriasis [11-13] as exemplified by demonstrated efficacy of Thiazolidinediones (TZDs) in treatment of psoriasis [14-18]. Metformin is an 'insulin sensitiser', lowers glucose levels without increasing insulin secretion. It has shown additional beneficial effects in adults with type 2 diabetes, including weight reduction, decreasing hyperinsulinemia, improving lipid profiles, augmented fibrinolysis and enhanced endothelial function [19-21], that all are usual metabilic abnormalities observed in subjects with MS. Therfore we anticipated that such pharmacological effects observed with metformin might be of use in psoriatic patients with MS. To the best of our knowledge no study till date has evaluated metformin and pioglitazone head to head in patients of psoriasis with MS. Present study was planned as comparative evaluation of safety \& efficay of metformin with pioglitazone in placebo controlled setting in patients of psoriasis with MS.

\section{Methods}

\section{Clinical trial design}

Study was approved by Institute Ethics committee, Post Graduate Institute of Medical Education and Research. This clinical trial was a single centre, parallel group, randomized, open label with blinded endpoint assessment of metformin, pioglitazone and placebo in psoriasis patients with MS satisfying inclusion and exclusion criteria. Our study is a part of larger study in which we evaluated the prevalence of MS in psoriasis. Then psoriasis patients having MS were divided into systemic (moderate to severe psoriasis, randomized into metformin and placebo arms) and topical treatment cohort (mild to moderate psoriasis, randomized into metformin, piolglitazone and placebo arms) and were evaluated for the effect of insulin sensitizers on disease parameters and MS. In this paper, we have discussed the results of topical treatment cohort.

All patients visiting psoriasis clinic at our Institute were screened for MS and other eligibility criteria. Both males and females, $>18$ years with plaque psoriasis [mild to moderate disease severity $(<10 \%$ of body surface area) [22], on treatment (had taken even a single application of topical therapy in the past) and treatment naïve (no past history of treatment for their disease)] and having MS i.e. the presence of three or more criteria of the modified National Cholesterol Education Program's Adult Treatment Panel III (NCEP ATP III) [23]: waist circumference $>90 \mathrm{~cm}$ in men and $>80 \mathrm{~cm}$ in women, hypertriglyceridemia $\geq$ $150 \mathrm{mg} / \mathrm{dl}$, high density lipoprotein (HDL) cholesterol $<40 \mathrm{mg} / \mathrm{dl}$ in males and $<50 \mathrm{mg} / \mathrm{dl}$ in females, blood pressure $\geq 130 / 85 \mathrm{mmHg}$ and fasting plasma glucose $\geq$ $110 \mathrm{mg} / \mathrm{dl}$ and willing to provide written informed consent were included in the study. Patients with severe disease, on topical therapy other than coal tar, pregnant or nursing women, significant hepatic impairment (serum bilirubin, AST, ALT and alkaline phosphatase $>1.5$ times the upper limit of normal), renal insufficiency - serum creatinine $\geq 1.5 \mathrm{mg} / \mathrm{dL}$ (men) or $\geq 1.4 \mathrm{mg} / \mathrm{dL}$ (women) and contraindication to metformin and pioglitazone were excluded from the study.

Clinical examination including psoriasis area and severity index (PASI) [22] scores and erythema, scaling and induration (ESI) scoring [24] was done. Clinical photographs of patients were taken at baseline and post treatment. Baseline investigations were done and eligible patients were randomized in an open label manner to either placebo (empty gelatin capsules), metformin $1000 \mathrm{mg}$ once daily (O.D) or pioglitazone $30 \mathrm{mg}$ O.D groups for a period of 12 weeks, after taking written 
informed consent. All patients were given standard topical $5 \%$ coal tar ointment in addition to study drugs. The randomization codes were computer generated. Randomization codes were concealed in an opaque envelope. The drug dispensation was done by a person who was not involved with the assessment of the study endpoints. Evaluation for efficacy parameters was done at 0 and 12 weeks. Safety evaluation was also done throughout the study.

\section{Efficacy evaluation}

Blinded end points assessment of the efficacy parameters was done at 12 weeks. Psoriasis lesions were evaluated using psoriasis area and severity index (PASI) scores and erythema, scaling and induration (ESI) score [24]. Each component of ESI was graded from 0 to 3; 0 - clear, 1 mild, 2 - moderate, 3 - severe. The most severe condition was given 9 points whereas absence of disease been given 0 points.

Also all the parameters of MS as defined by modified National Cholesterol Education Program's Adult Treatment Panel III (NCEPIII) criteria [23] were assesed at baseline and 12 weeks. Serum IL- 6 and TNF- $\alpha$ levels was done at 0 and 12 weeks in subgroup (10, 7 and 9 patients in placebo, metformin and pioglitazone groups respectively) of patients by Human ELISA kit (RayBiotech, Inc. Georgia. USA).

The primary efficacy end point was mean change in PASI, ESI and PGA scores from baseline after 12 weeks of therapy between three treatment groups given along with standard treatment for psoriasis. The Secondary efficacy end point were number of parameters of MS improved, change in individual parameters of MS, IL -6 and TNF $-\alpha$ from baseline after 12 weeks of treatment with metformin, pioglitazone or placebo. The change in Physician Global Assessment (PGA) from baseline and percentage of patients achieving $75 \%$ reduction in ESI and PGA score in the three treatment groups were other end points.

\section{Sample size calculation}

Assuming a standard deviation of 2 in PASI scores, and a difference of 2 in PASI score between drug and placebo arm at 12 weeks to be clinically significant at $\alpha=$ 0.05 and with $80 \%$ power, a sample size of 16 patients per group has been calculated and with a dropout rate of about $20 \%, 19$ patients will be required to be included in each group.

\section{Statistical analysis}

Data was expressed as Mean \pm SD (95\% confidence intervals), numbers (percentages) and median (interquartile range). Baseline characteristics between three treatment groups were compared using one way ANOVA for numerical variables and Chi-Square test for categorical variables. Analysis was carried out using intention to treat principle.

Mean changes in PASI, ESI and PGA scores at 12 weeks from baseline between three treatment groups were compared using One way ANOVA followed by post hoc Scheffe. Chi-Square test or Fischer's Exact test was used to compare the categorical variables. Intra group comparison of mean changes in individual parameters of MS and lipid profile was carried out by paired $T$-test and inter group comparison by One way ANOVA. Difference in changes in serum levels of IL- 6 and TNF- $\alpha$ between the groups was done by One way ANOVA.

Results were analyzed as Intention-to-treat analysis with last observation carry forward (LOCF). A two-sided $P$-value less than 0.05 was considered as statistically significant.

\section{Results}

A total of 83 consecutive adult psoriasis patients with MS were screened from June 2010 to April 2011 (Fig. 1). Out of 83 patients, 23 were excluded from the study. 23, 16 and 21 patients were randomized to placebo, pioglitazone and metformin treatment groups respectively. Disposition of patients and reasons for withdrawal were summarized in Fig. 1. Hence, 21 patients in placebo arm, 16 in pioglitazone and 18 patients in metformin arm completed the study. As Intention to treat analysis with last observation carry forward (LOCF) was done, so all the subjects as randomized were included for final analysis.

No significant difference was observed in baseline demographics and MS characteristics among three treatment groups except past history of remission (Table 1).

\section{ESI and PGA scores and parameters of Metabolic Syndrome (MS)}

Statistically significant improvement was observed in PASI, ESI and PGA scores in pioglitazone $(P$ values PASI $=0.001$, ESI $=0.002$, PGA $=0.008)$ and metformin groups $(P$ values $-\mathrm{PASI}=0.001, \mathrm{ESI}=0.016, \mathrm{PGA}=$ 0.012) as compared to placebo (Fig. 2). There was statistically significant difference in percentage of parameters of MS improved following 12 weeks of treatment in pioglitazone $(15 \%)$ and metformin $(16.2 \%)$ groups as compared to placebo (3.5 \%) (Fig. 3). Statistically significant difference in percentage of patients achieving $75 \%$ reduction in PASI and ESI scores in metformin ( $p$ value PASI $=0.001, \quad E S I=0.001)$ and pioglitazone groups $(p$ value - PASI $=0.001$, ESI $=0.001$ ) (Fig. 4). Statistically significant improvement is observed in FPG, total cholesterol and triglycerides levels (Table 2) in metformin and pioglitazone arms as compared to placebo. Significant improvement was also observed in percentage of 


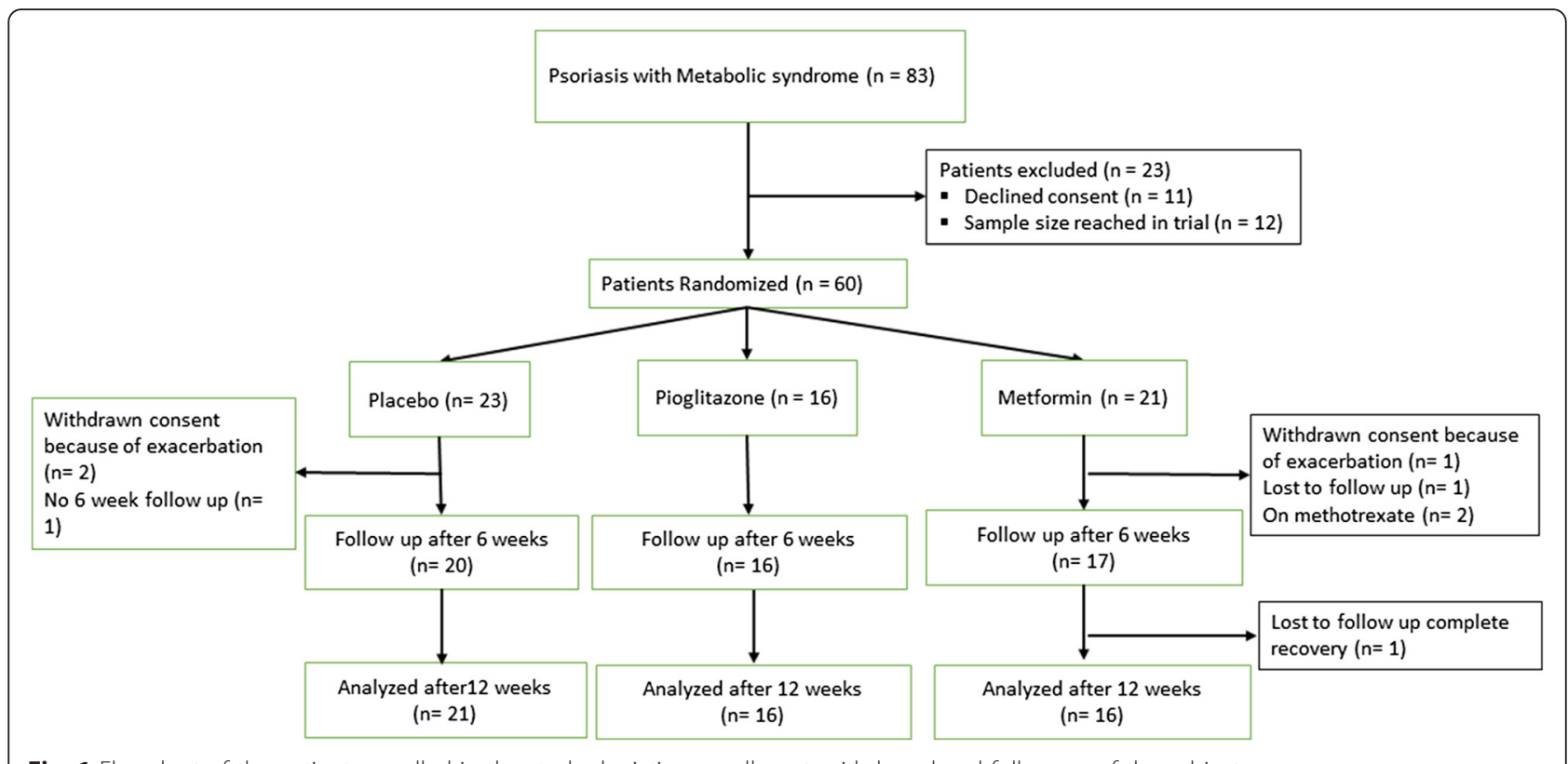

Fig. 1 Flowchart of the patients enrolled in the study depicting enrollment, withdrawal and follow up of the subjects

patients achieving $75 \%$ reduction in PGA scores (Fig. 4) and change in weight and waist circumference in metformin group as compared to placebo (Table 2). Significant improvement was observed in weight, BMI, waist circumference, FPG, triglycerides and total cholesterol after treatment with metformin (Table 2). Similarly improvement was seen in FPG, triglyceride levels, systolic blood pressure (SBP), diastolic blood pressure (DBP), total cholesterol and LDL cholesterol levels after treatment with pioglitazone for 12 weeks (Table 2). No significant change in the IL- 6 and TNF- $\alpha$ levels among three groups (Fig. 5).

No significant difference in the mean number of adverse events in three groups except for weight gain between metformin and pioglitazone (Table 3).

\section{Discussion}

Baseline characteristics were similar among three treatment groups except for percentage of individuals having remission. The difference observed in baseline characteristic is unlikely to be of clinical significance and could not have accounted for the higher efficacy observed in metformin and pioglitazone groups in comparison to placebo group. All patients were given topical $5 \%$ coal $\operatorname{tar}$ treatment. As the compliance achieved is around $90 \%$, which is ensured by direct questioning and pill count, it is less likely that topical treatment with $5 \%$ coal tar would have resulted in the differences in efficacy among three treatment groups. In our study, metformin and pioglitazone cause significant improvement in PASI, ESI and PGA scores as compared to placebo.
In metformin, pioglitazone and placebo group, 52.4 \%, $50 \%$ and $17.4 \%$ of the patients had complete improvement in MS respectively (metformin vs placebo - OR (95 \% CI), $5.2(1.3-20.7), P$ value $=0.019$; pioglitazone vs placebo $-(\mathrm{OR}(95 \% \mathrm{CI})=4.8(1.1-20.4), P$ value $=$ 0.036; metformin vs pioglitazone $-(\mathrm{OR}(95 \% \mathrm{CI})=0.9$ $(0.2-3.3), P$ value $=0.886)$. Therefore, metformin and pioglitazone beneficial effect on MS parameters might be accounted for the improved efficacy in psoriasis disease itself.

Clinical studies had also demonstrated the proof of efficacy of TZDs in psoriasis. Pioglitazone had demonstrated superior efficacy to placebo group alone as well as in combination therapy with acitretin in psoriasis patients $[14,15]$. Two open label studies $[16,17]$ had demonstrated marked improvement in psoriasis lesions with troglitazone in chronic plaque type psoriasis patients. Robertshaw and Friedman [18] have also demonstrated excellent improvement with pioglitazone in 4 out of 5 patients with chronic plaque type psoriasis in an open label, pilot study.

Study done by Bongartz et al (2005) with pioglitazone $60 \mathrm{mg} /$ day for 12 weeks in psoriatic arthritis patients with tender and swollen joints, demonstrated $60 \%$ of the patients met the psoriatic arthritis response criterion. Mean percentage reduction in PASI was $38 \%$, along with median tender joint count decreased from 12-4 and median swollen joint count from 5 to $2(P<0.05$ for both) [25]. The observed higher percentage reduction in ESI and PGA scores in our study is thus expected and is a demonstration of pioglitazone efficacy. 
Table 1 Baseline characteristics of three treatment groups

\begin{tabular}{|c|c|c|c|c|}
\hline Baseline characteristics & Placebo $(n=23)$ & Metformin $(n=21)$ & Pioglitazone $(n=16)$ & $p$-value \\
\hline Age (years) Mean $( \pm S D)$ & $46.9( \pm 10.4)$ & $45.1( \pm 13.0)$ & $44.0( \pm 12.9)$ & 0.747 \\
\hline Male/Females, $n$ (\%) & $14 / 9(60.9 / 39.1)$ & $12 / 9(57.1 / 42.9)$ & 9/7 (56.3/43.7) & 0.950 \\
\hline Total duration of disease (years) Mean $( \pm S D)$ & $9.1( \pm 8.6)$ & $6.0( \pm 6.9)$ & $6.9( \pm 11.2)$ & 0.492 \\
\hline Seasonal Exacerbation, $n$ (\%) & $13(56.5)$ & $13(61.9)$ & $6(37.5)$ & 0.313 \\
\hline Seasonal improvement, $n$ (\%) & $13(56.5)$ & $13(61.9)$ & $5(31.3)$ & 0.152 \\
\hline Remission, $n(\%)$ & $21(91.3)$ & $11(52.4)$ & $10(62.5)$ & 0.014 \\
\hline Nail involvement, $n(\%)$ & $17(73.9)$ & $13(61.9)$ & $12(75.0)$ & 0.602 \\
\hline Joint involvement, $n$ (\%) & $7(30.4)$ & $5(23.8)$ & $4(25.0)$ & 0.870 \\
\hline $\mathrm{DM}, n(\%)$ & $2(8.7)$ & $3(14.3)$ & $3(18.6)$ & 0.653 \\
\hline HTN, $n(\%)$ & $11(47.8)$ & $10(47.6)$ & $5(31.3)$ & 0.523 \\
\hline Family H/O Psoriasis, $n$ (\%) & $4(17.4)$ & $3(14.3)$ & $0(0)$ & 0.225 \\
\hline Alcohol, $n(\%)$ & $6(26.1)$ & $8(38.1)$ & $6(37.5)$ & 0.643 \\
\hline Smoking, $n(\%)$ & $3(13.0)$ & $3(14.3)$ & $1(6.3)$ & 0.727 \\
\hline Vegetarian, $n(\%)$ & $10(43.8)$ & $11(52.4)$ & $12(75.0)$ & 0.144 \\
\hline BMI $\left(\mathrm{kg} / \mathrm{m}^{2}\right)$, Mean $( \pm \mathrm{SD})$ & $29.5( \pm 3.7)$ & $27.6( \pm 3.7)$ & $27.4( \pm 4.3)$ & 0.151 \\
\hline Waist Circumference $(\mathrm{cm})$, Mean $( \pm \mathrm{SD})$ & $105.3( \pm 9.1)$ & $99.0( \pm 9.9)$ & $100.2( \pm 8.7)$ & 0.70 \\
\hline ESI, Mean ( \pm SD) & $5.9( \pm 1.6)$ & $5.3( \pm 1.5)$ & $5.4( \pm 1.3)$ & 0.412 \\
\hline PGA, Mean $( \pm S D)$ & $3.4( \pm 0.9)$ & $3.1( \pm 0.8)$ & $3.2( \pm 0.8)$ & 0.476 \\
\hline FPG $(\mathrm{mg} / \mathrm{dl})$, Mean $( \pm \mathrm{SD})$ & $97.6( \pm 20.8)$ & $101.9( \pm 35.1)$ & $103.4( \pm 28.9)$ & 0.797 \\
\hline Total Cholesterol (mg/dl), Mean ( \pm SD) & $184.4( \pm 37.5)$ & $206.9( \pm 36.2)$ & $207.2( \pm 42.3)$ & 0.95 \\
\hline Triglycerides (mg/dl), Mean ( $\pm S D)$ & $181.8( \pm 61.3)$ & $194.3( \pm 63.1)$ & $200.1( \pm 55.9)$ & 0.623 \\
\hline HDL (mg/dl), Mean ( \pm SD) & $45.1( \pm 13.5)$ & $44.3( \pm 6.6)$ & $45.0( \pm 9.7)$ & 0.968 \\
\hline LDL (mg/dl), Mean ( \pm SD) & $107.6( \pm 35.7)$ & $126.1( \pm 29.1)$ & $123.1( \pm 42.3)$ & 0.194 \\
\hline SBP $(m m H g)$, Mean $( \pm S D)$ & $130.4( \pm 11.5)$ & $130.6( \pm 12.9)$ & $135.6( \pm 11.5)$ & 0.344 \\
\hline DBP $(m m H g)$, Mean $( \pm S D)$ & $84.7( \pm 7.9)$ & $85.9( \pm 7.9)$ & $85.6( \pm 8.5)$ & 0.875 \\
\hline Calcium channel blockers, $n(\%)$ & $5(21.7)$ & $3(14.3)$ & $3(18.6)$ & 0.815 \\
\hline Beta blockers, $n(\%)$ & $2(8.7)$ & $1(4.8)$ & $0(0)$ & 0.471 \\
\hline Angiotensin receptor blockers, $n(\%)$ & $2(8.7)$ & $2(9.5)$ & $0(0)$ & 0.456 \\
\hline ACE inhibitors, $n(\%)$ & $1(4.3)$ & $0(0)$ & $1(6.3)$ & 0.543 \\
\hline Diuretics, $n(\%)$ & $0(0)$ & $0(0)$ & $1(6.3)$ & 0.247 \\
\hline Sulfonylureas, n (\%) & $2(8.7)$ & $0(0)$ & $1(6.3)$ & 0.403 \\
\hline Anxiolytics, $n(\%)$ & $1(4.3)$ & $1(4.8)$ & $0(0)$ & 0.684 \\
\hline Lithium, n (\%) & $1(4.3)$ & $0(0)$ & $0(0)$ & 0.441 \\
\hline Antidepressants, $n(\%)$ & $1(4.3)$ & $2(9.5)$ & $0(0)$ & 0.413 \\
\hline Insulin, n (\%) & $0(0)$ & $1(4.8)$ & $0(0)$ & 0.389 \\
\hline Modafinil, n (\%) & $0(0)$ & $1(4.8)$ & $0(0)$ & 0.389 \\
\hline NSAIDS, n (\%) & $0(0)$ & $1(4.8)$ & $0(0)$ & 0.389 \\
\hline Ca, Vitamin D, n (\%) & $0(0)$ & $1(4.8)$ & $0(0)$ & 0.389 \\
\hline Steroids, $n(\%)$ & $0(0)$ & $0(0)$ & $1(6.3)$ & 0.247 \\
\hline Beta 2 agonists, $n$ (\%) & $0(0)$ & $0(0)$ & $1(6.3)$ & 0.247 \\
\hline
\end{tabular}

$D M$ diabetes mellitus, HTN hypertension, BMI body mass index, ESI erythema, scaling and Induration, PFA physician global assessment, FPG fasting plasma glucose, $H D L$ high density lipoprotein, $L D L$ low density lipoprotein, $S B P$ systolic blood pressure, $D B P$ diastolic blood pressure, $A C E$ inhibitors angiotensin converting enzyme inhibitors

Values are presented as Mean $( \pm \mathrm{SD})$ or $n(\%)$ 


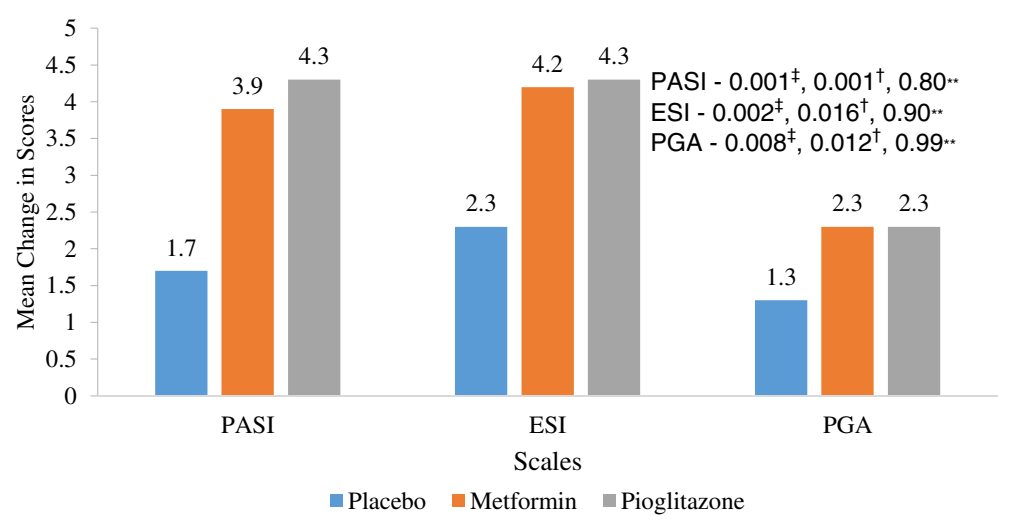

Fig. 2 Mean change in PASI, ESI and PGA scores in three treatment groups from baseline (Intention to treat Analysis). II=Inter-group comparisons for PASI, ESI and PGA scores at 12 weeks as compared to baseline was carried out by One Way ANOVA, post hoc test used Scheffe; $\dagger=$ metformin vs placebo, $\neq=$ Pioglitazone vs placebo, ${ }^{* *}=$ metformin vs pioglitazone. PASI - Psoriasis area and severity index, ESI - Erythema, Scaling and Induration, PGA - Physician Global Assessmenty

To the best of our knowledge, effect of metformin in psoriasis patients with MS as done in our study has not been explored earlier. Our study has demonstrated improved efficacy of metformin in psoriasis disease itself as well as features of MS. A population based case control study Brauchli et al estimated the decreased risk of developing a first-time psoriasis diagnosis with metformin use as compared to matched controls [OR $=0.77$ (95\% CI - 0.62-0.96)] [26]. One case of psoriasiform drug eruption associated with metformin usage has been observed, which on dechallenge and rechallenege leads to improvement and reappearance of lesions respectively [27]. In view of the case report, it has to be kept in mind that there can be clinical worsening of psoriasis with the use of metformin for treatment of psoriasis.
The anti-proliferative [16, 28], pro-differentiating [29], anti-inflammatory $[11,12,30]$ and anti-angiogenic [31, 32] effects of TZDs seen in other studies may underlie the observed beneficial anti-psoriatic effects of pioglitazone. Metformin act through activation of adenosine monophosphate-activated protein kinase (AMPK) in extracellular signal-related kinase (ERK1/2) signaling pathway leading to cell cycle arrest and therefore inhibition of cell proliferation, hallmark of psoriasis [33]. AMPK activation not only inhibits iNOS, dendritic, T cell and monocyte/macrophage activation but also activates $\mathrm{IL}-10$ and TGF- $\beta$, thereby exerting its antiinflammatory action [34]. The anti-proliferative and anti-inflammatory action of metformin might have resulted in improvement of psoriasis.

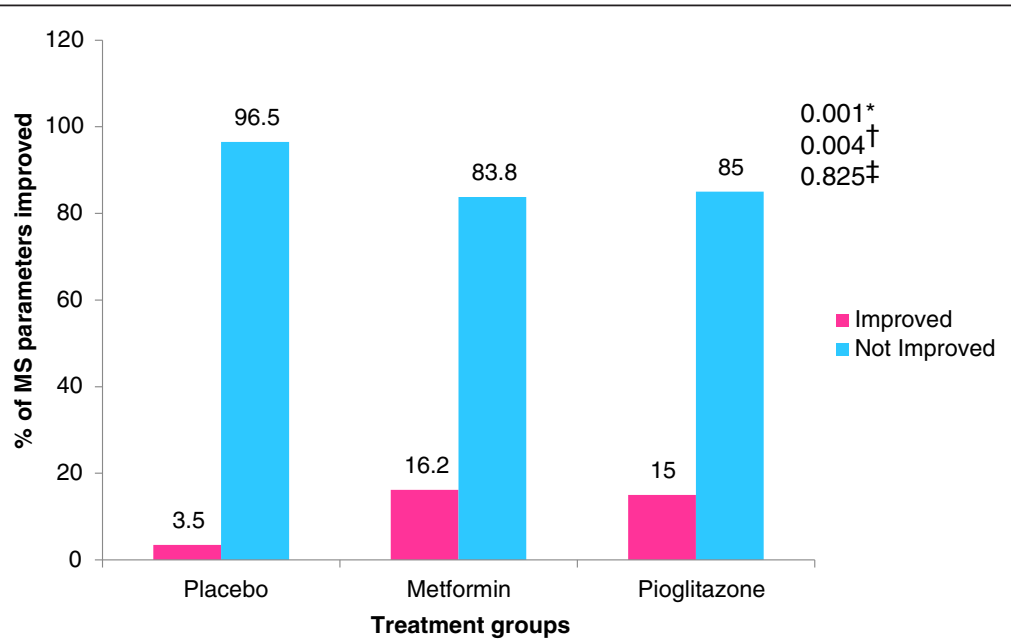

Fig. 3 Percentage of parameters of metabolic syndrome (MS) improved following 12 weeks of treatment in placebo, metformin and pioglitazone groups from baseline (Intention to treat Analysis). Inter-group comparisons for percentage of parameters of metabolic syndrome improved carried out by Chi-square test. ${ }^{*}=$ Placebo vs metformin, $\dagger=$ placebo vs pioglitazone, $\neq=$ metformin vs pioglitazone; $\mathrm{MS}=$ Metabolic syndrome 


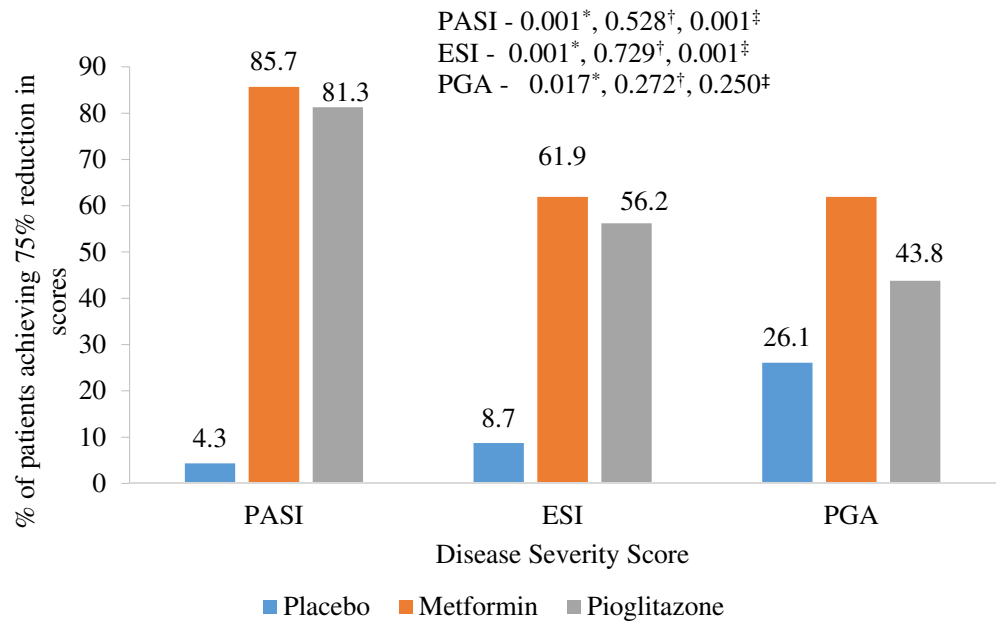

Fig. 4 Percentage of patients achieving $75 \%$ reduction in PASI, ESI and PGA scores in placebo, metformin and pioglitazone groups from baseline (Intention to treat Analysis). Inter-group comparisons for $75 \%$ reduction in PASI, ESI and PGA scores between three treatment groups carried out by Chi-square test. ${ }^{*}=$ placebo vs metformin, $\dagger=$ metformin vs pioglitazone, $\neq=$ placebo vs pioglitazone. PASI - Psoriasis area and severity index, ESI - Erythema, Scaling and Induration, PGA - Physician Global Assessment

In diabetics, metformin had shown to decrease $\mathrm{HbA}_{1 \mathrm{C}}$, total and LDL cholesterol, serum triglycerides, fasting insulin levels and improves HDL cholesterol [35-37]. Metformin has shown to improve cardiovascular outcomes by mitigating apoptosis [38]. These results are similar to the results observed in our study. In our study, although an increase in mean weight and BMI was observed with pioglitazone but decrease in mean waist circumference was also observed. Clinical studies had shown despite the weight gain reported in all the studies, which may equal as much as $0.5 \mathrm{~kg}$ per month for monotherapy, mean waist to hip ratio remains invariably unchanged. In one study, favorable effect on body fat distribution was demonstrated when patients with type

Table 2 Mean Change in individual parameters of metabolic syndrome after 12 weeks of treatment in three treatment groups from baseline (Intention to treat Analysis)

\begin{tabular}{|c|c|c|c|c|c|c|c|}
\hline \multirow{2}{*}{$\begin{array}{l}\text { Treatment } \\
\text { Parameters }\end{array}$} & \multicolumn{2}{|l|}{ Placebo $(n=23)$} & \multicolumn{2}{|l|}{ Metformin $(n=21)$} & \multicolumn{2}{|l|}{ Pioglitazone $(n=16)$} & \multirow{2}{*}{$\begin{array}{l}\text { ANOVA with post hoc } \\
\text { Tukey's }{ }^{b} \\
\text { Between groups, } d f=2, p \\
\text { value }\end{array}$} \\
\hline & $\begin{array}{l}\text { Mean change [Mean } \\
\pm \mathrm{SD} \text { ] }\end{array}$ & $\begin{array}{l}p \\
\text { value }^{a}\end{array}$ & $\begin{array}{l}\text { Mean change [Mean } \\
\pm S D \text { ] }\end{array}$ & $\begin{array}{l}p \\
\text { value }^{a}\end{array}$ & $\begin{array}{l}\text { Mean change [Mean } \\
\pm S D \text { ] }\end{array}$ & $\begin{array}{l}p \\
\text { value }^{a}\end{array}$ & \\
\hline Weight (kg) & $-0.6 \pm 3.1$ & 0.338 & $1.1 \pm 1.9$ & $0.016^{f}$ & $-0.4 \pm 1.7$ & 0.324 & $0.048^{c}, 0.970^{d}, 0.129^{e}$ \\
\hline BMI $\left(\mathrm{kg} / \mathrm{m}^{2}\right)$ & $-0.1 \pm 1.4$ & 0.663 & $0.4 \pm 0.7$ & $0.016^{f}$ & $-0.2 \pm 0.7$ & 0.370 & $0.186^{c}, 0.995^{d}, 0.210^{e}$ \\
\hline $\begin{array}{l}\text { Waist circumference } \\
(\mathrm{cm})\end{array}$ & $-0.9 \pm 4.0$ & 0.314 & $1.9 \pm 2.7$ & $0.003^{f}$ & $0.9 \pm 2.3$ & 0.119 & $0.013^{c}, 0.200^{d}, 0.606^{e}$ \\
\hline FPG $(\mathrm{mg} / \mathrm{dl})$ & $2.2 \pm 10.0$ & 0.312 & $15.2 \pm 19.2$ & $0.002^{f}$ & $20.5 \pm 17.4$ & $<0.001^{\mathrm{f}}$ & $0.021^{c}, 0.002^{d}, 0.577^{e}$ \\
\hline Triglycerides (mg/dl) & $1.1 \pm 43.3$ & 0.903 & $44.3 \pm 45.4$ & $<0.001^{f}$ & $53.3 \pm 36.9$ & $<0.001^{f}$ & $0.004^{c}, 0.001^{d}, 0.798^{e}$ \\
\hline $\mathrm{HDL}(\mathrm{mg} / \mathrm{dl})$ & $-1.7 \pm 6.6$ & 0.221 & $-1.9 \pm 4.6$ & 0.060 & $-1.5 \pm 9.6$ & 0.544 & $0.992^{c}, 0.994^{d}, 0.974^{e}$ \\
\hline $\mathrm{SBP}(\mathrm{mm} \mathrm{Hg})$ & $0.0 \pm 8.6$ & 1.000 & $1.7 \pm 6.7$ & 0.257 & $5.1 \pm 6.3$ & $0.005^{f}$ & $0.725^{c}, 0.094^{d}, 0.354^{e}$ \\
\hline $\mathrm{DBP}(\mathrm{mm} \mathrm{Hg})$ & $0.3 \pm 7.9$ & 0.876 & $1.7 \pm 4.2$ & 0.077 & $4.1 \pm 5.5$ & $0.009^{f}$ & $0.546^{c}, 0.085^{d}, 0.475^{e}$ \\
\hline $\begin{array}{l}\text { Total Cholesterol } \\
(\mathrm{mg} / \mathrm{dl})\end{array}$ & $1.4 \pm 29.2$ & 0.816 & $21.8 \pm 25.2$ & $0.001^{f}$ & $24.0 \pm 29.5$ & $0.005^{f}$ & $0.049^{c}, 0.042^{d}, 0.970^{e}$ \\
\hline LDL (mg/dl) & $-5.9 \pm 28.3$ & 0.324 & $6.6 \pm 20.0$ & 0.146 & $9.8 \pm 11.6$ & $0.004^{f}$ & $0.151^{c}, 0.079^{d}, 0.898^{e}$ \\
\hline
\end{tabular}

FPG fasting plasma glucose, $H D L$ high density lipoprotein, $S B P$ systolic blood pressure, $D B P$ diastolic blood pressure, $B M I$ body mass index, $L D L$ low density lipoprotein

a Intra-group comparisons for weight, BMI, individual parameters of lipid profile and metabolic syndrome carried out by Paired $T$-test

${ }^{b}$ Inter-group comparisons for individual parameters carried out by One way ANOVA, post hoc Tukey's test

c Metformin vs placebo

d pioglitazone vs placebo

e metformin vs pioglitazone

${ }^{f}$ statistically significant difference compared to baseline 


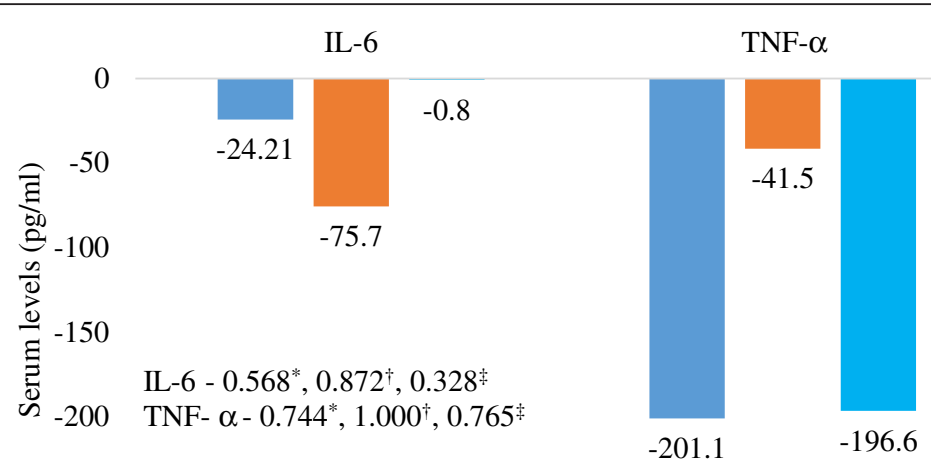

$-250$

\section{Cytokines}

\section{- Placebo $\quad$ Metformin $\square$ Pioglitazone}

Fig. 5 Mean decrease in levels of IL-6 and TNF-a in three treatment groups from baseline in subgroup of patients (Intention to treat Analysis). Values are expressed as Mean \pm SD. Inter-group comparisons for IL- 6 and TNF-a carried out by One way ANOVA, *- Metformin vs placebo, + - pioglitazone vs placebo, $\neq$ - metformin vs pioglitazone, IL-6 - Interleukin-6, TNF- $a$ - Tumor necrosis factor-a

Table 3 Adverse events observed during the study in placebo, metformin and pioglitazone treatment groups in topical treatment arm

\begin{tabular}{|c|c|c|c|c|}
\hline Adverse Event & Placebo $(N=23)$ & Metformin $(N=21)$ & Pioglitazone $(N=16)$ & $P$ value (Fischer's Exact test) \\
\hline Redness & 1 & 1 & 0 & $>0.99^{a},>0.99^{b},>0.99^{c}$ \\
\hline Pain & 1 & 0 & 0 & $>0.99^{a},>0.99^{b},>0.99^{c}$ \\
\hline Hyperpigmentation & 7 & 5 & 4 & $0.74^{a},>0.99^{b}>0.99^{c}$ \\
\hline Hypopigmentation & 0 & 1 & 1 & $0.477^{a}, 0.41^{b}>0.99^{c}$ \\
\hline Exacerbation & 2 & 3 & 0 & $0.658^{a}, 0.503^{b}, 0.243^{c}$ \\
\hline Hypothyroidism & 1 & 0 & 0 & $>0.99^{a},>0.99^{b}$ \\
\hline Edema & 0 & 0 & 2 & $0.162^{b}, 0.180^{c}$ \\
\hline c/o Weight Gain & 0 & 0 & 2 & $0.162^{b}, 0.180^{c}$ \\
\hline Anemia & 0 & 0 & 0 & - \\
\hline Abdominal Pain & 0 & 1 & 0 & $0.477^{a},>0.99^{c}$ \\
\hline Headache & 0 & 0 & 0 & - \\
\hline Gastritis & 0 & 0 & 0 & - \\
\hline Nausea & 0 & 0 & 0 & - \\
\hline Vomiting & 0 & 0 & 0 & - \\
\hline Dizziness & 0 & 0 & 0 & - \\
\hline Diarrhea & 0 & 1 & 0 & $0.477^{a},>0.99^{c}$ \\
\hline Heartburn & 0 & 1 & 0 & $0.477^{\mathrm{a}},>0.99^{c}$ \\
\hline$>3$ times SGOT/SGPT & 0 & 0 & 0 & - \\
\hline Slight increase in SGOT/SGPT & 0 & 0 & 0 & - \\
\hline Increased TLC & 0 & 0 & 0 & - \\
\hline Weight gain > 1 kg & 8 & 3 & 8 & $0.169^{a}, 0.509^{b}, 0.030^{c}$ \\
\hline Recurrence after 3 months & 4 & 6 & 5 & $0.377^{\mathrm{a}}, 0.312^{\mathrm{b}}, 0.860^{\mathrm{c}}$ \\
\hline
\end{tabular}

Inter group comparison between groups was done by Fischer's Exact test; $p$ - value $\leq 0.05$ was considered statistically significant

a placebo vs metformin

b placebo vs pioglitazone

c metformin vs pioglitazone 
II diabetes were treated with pioglitazone $45 \mathrm{mg} /$ day for 16 weeks [39]. MR imaging revealed that pioglitazone decreased visceral fat area and increased subcutaneous fat mass. With $1 \mathrm{H}-\mathrm{MR}$ spectroscopy in same group of patients, significant decrease in liver fat content was demonstrated. Thus, thiazolidinedione's (TZDs) have favorable effects on body fat distribution, intra hepatic fat content and adipose tissue metabolism, all resulting in increased insulin sensitivity.

Our study had revealed a mean fall of $20.5 \mathrm{mg} / \mathrm{dl}$ in FPG in psoriasis patients with MS with pioglitazone $30 \mathrm{mg} /$ day. PROFIT-J study have shown improvement in glycemic control, DBP and lipid profile [40]. In clinical trials, pioglitazone monotherapy at a dose of $30 \mathrm{mg} /$ day revealed a dose dependent lowering of FPG by 1.0 $3.1 \mathrm{mmol} / \mathrm{L}$ and $\mathrm{HbA}_{1 \mathrm{C}}$ reductions ranging between 0.3 and $1.08 \%$ from baseline, significant when compared with placebo [41-45]. Pioglitazone increases peripheral insulin sensitivity, enhancing both splanchnic and peripheral glucose uptake, in patients with type II diabetes in randomized, placebo controlled, 12-26 weeks trial [40, 46, 47]. We observed a mean decrease in serum triglycerides, total cholesterol and LDL cholesterol of 53.3, 24 and $9.8 \mathrm{mg} / \mathrm{dl}$ respectively, with pioglitazone $30 \mathrm{mg} /$ day. Lipid profiles generally improved in pioglitazone recipients in three placebo controlled 12-26 week trial [41, 42, 48]. Favorable increases in HDL cholesterol were greater in pioglitazone than placebo recipients in three trials $[40,42,48]$.

Mean reduction in SBP and DBP of 5.1 and $4.1 \mathrm{mmHg}$ respectively was measured in pioglitazone group in our study, which was significant as compared to baseline. In a review article by Giles et al, the observed magnitude of reduction was $4-5 \mathrm{mmHg}$ in SBP and $2-4 \mathrm{mmHg}$ in DBP, which were sufficient to significantly reduce cardiovascular event rates [49]. The decrease in cardiovascular risk factors namely lipid profile and blood pressure in our study might contribute to the overall decrease in diabetes and cardiovascular mortality in psoriasis patients with MS.

Increased risk of bladder cancer with the long term use of pioglitazone as shown in French cohort study [50], UK nested case control study [51] and interim results of longitudinal study [52]. However, the 10-year final analysis of longitudinal study [52] did not show any statistically significant findings of increased risk of bladder cancer with long term use of pioglitazone [53]. Similarly, no statistically significant association was found in two Taiwanese studies $[54,55]$. Infact, TZDs have shown to decrease the risk of breast, brain, colorectal, ear-nosethroat, kidney, liver, lung, lymphatic, prostate, stomach and uterus cancer significantly [56]. FDA although issued a safety warning, has not withdrawn the drug.

There are no significant differences in metformin as compared to pioglitazone with regard to improvement in psoriasis and MS parameters. But there is significant reduction in weight with the use of metformin and due to controversy of increased risk of bladder cancer associated with pioglitazone; metformin can be preferred over pioglitazone in psoriasis patients with MS.

In subgroup analysis, $10 \%$ of patients in placebo, $14.3 \%$ in metformin and $37.5 \%$ of patients in pioglitazone subgroup had no decline or rather increase in the levels of IL- 6 and TNF- $\alpha$, consistent with the relapse of psoriasis in these patients in next 6 months. Remitting relapsing nature of the disease might be accounted for no significant change in the IL- 6 and TNF- $\alpha$ level.

Randomization and placebo control are the strengths of our study. The study also has some limitations. Intermediate dose of pioglitazone $(30 \mathrm{mg} /$ day $)$ and metformin (1000 mg/day) was used in the study. Secondly, it was an open label study, although blinded end point assessment was done.

\section{Conclusion}

Insulin sensitizers have shown improvement in the parameters of MS as well as psoriasis disease. With further evaluation in clinical studies, Insulin sensitizers can be used for the management of psoriasis patients with MS.

\section{Acknowledgement \\ Thankful to Dr. Sunil Dogra and Late Dr. Inderjeet Kaur for constant support and excellent academic inputs in the study. \\ Funding \\ This study was carried out in Post graduate institute of medical sciences, Chandigarh. This study was part of dissertation for degree of Doctrine of Medicine in Clinical Pharmacology. 'This study was not supported financially by any pharmaceutical company.}

Availability of data and materials

All the data can be requested from authors.

\section{Authors' contribution}

SS and AB conceptualize the study design, SS drafted the protocol with the approval of AB. SS collected the data and did statistical analysis. All authors read and approve the final manuscript.

\section{Competing interests}

The authors declare that they have no competing interests.

\section{Consent for publication}

Not applicable.

\section{Ethics approval and consent to participate}

We also declare that the study was assessed and approved by the Institutional Ethics Committee, Post Graduate Institute of Medical Education and Research, Chandigarh and that letter of approval is available with us for examination. Ethics committee letter number for the approval of study is MS/1145/DM/8229, dated $1^{\text {st }}$ April 2010. From all patients written informed consent was taken before randomization.

\section{Author details}

'Department of Pharmacology, All India Institute of Medical Sciences (AlIMS), Jodhpur 342005, India. '2Department of Endocrinology, Post Graduate Institute of Medical Education and Research (PGIMER), Chandigarh 160012, India. 


\section{Received: 27 January 2016 Accepted: 10 August 2016}

\section{Published online: 17 August 2016}

\section{References}

1. Sommer DM, Jenisch S, Suchan M, Christophers E, Weichenthal M. Increased prevalence of the metabolic syndrome in patients with moderate to severe psoriasis. Arch Dermatol Res. 2006;298(7):321-8.

2. Gelfand JM, Yeung H. Metabolic syndrome in patients with psoriatic disease. J Rheumatol Suppl. 2012;89:24-8.

3. Neimann AL, Shin DB, Wang X, Margolis DJ, Troxel AB, Gelfand JM. Prevalence of cardiovascular risk factors in patients with psoriasis. J Am Acad Dermatol. 2006;55(5):829-35.

4. Executive Summary of The Third Report of The National Cholesterol Education Program (NCEP). Expert panel on detection, evaluation, and treatment of high blood cholesterol in adults (Adult Treatment Panel III). JAMA. 2001;285(19):2486-97.

5. Armstrong EJ, Harskamp CT, Armstrong AW. Psoriasis and major adverse cardiovascular events: a systematic review and meta-analysis of observational studies. J Am Heart Assoc. 2013;2(2):e000062.

6. Patel RV, Shelling ML, Prodanovich S, Federman DG, Kirsner RS. Psoriasis and vascular disease-risk factors and outcomes: a systematic review of the literature. J Gen Intern Med. 2011;26(9):1036-49.

7. Wilson PW, D'Agostino RB, Parise H, Sullivan L, Meigs JB. Metabolic syndrome as a precursor of cardiovascular disease and type 2 diabetes mellitus. Circulation. 2005;112(20):3066-72.

8. Eckel RH, Grundy SM, Zimmet PZ. The metabolic syndrome. Lancet. 2005; 365(9468):1415-28

9. Wannamethee SG, Shaper AG, Lennon L, Morris RW. Metabolic syndrome vs Framingham Risk Score for prediction of coronary heart disease, stroke, and type 2 diabetes mellitus. Arch Intern Med. 2005;165(22):2644-50.

10. Sterry W, Strober BE, Menter A. Obesity in psoriasis: the metabolic, clinical and therapeutic implications. Report of an interdisciplinary conference and review. Br J Dermatol. 2007;157(4):649-55.

11. Ricote M, Li AC, Willson TM, Kelly CJ, Glass CK. The peroxisome proliferatoractivated receptor-gamma is a negative regulator of macrophage activation. Nature. 1998;391(6662):79-82.

12. Jiang C, Ting AT, Seed B. PPAR-gamma agonists inhibit production of monocyte inflammatory cytokines. Nature. 1998;391(6662):82-6.

13. Malhotra S, Bansal D, Shafiq N, Pandhi P, Kumar B. Potential therapeutic role of peroxisome proliferator activated receptor-gamma agonists in psoriasis. Expert Opin Pharmacother. 2005;6(9):1455-61.

14. Shafiq N, Malhotra S, Pandhi P, Gupta M, Kumar B, Sandhu K. Pilot trial: Pioglitazone versus placebo in patients with plaque psoriasis (the P6). Int J Dermatol. 2005:44(4):328-33.

15. Mittal R, Malhotra S, Pandhi P, Kaur I, Dogra S. Efficacy and safety of combination Acitretin and Pioglitazone therapy in patients with moderate to severe chronic plaque-type psoriasis: a randomized, double-blind, placebo-controlled clinical trial. Arch Dermatol. 2009; 145(4):387-93.

16. Ellis CN, Varani J, Fisher GJ, Zeigler ME, Pershadsingh HA, Benson SC, et al. Troglitazone improves psoriasis and normalizes models of proliferative skin disease: ligands for peroxisome proliferator-activated receptor-gamma inhibit keratinocyte proliferation. Arch Dermatol. 2000; 136(5):609-16.

17. Pershadsingh HA, Sproul JA, Benjamin E, Finnegan J, Amin NM. Treatment of psoriasis with troglitazone therapy. Arch Dermatol. 1998;134(10):1304-5.

18. Robertshaw H, Friedmann PS. Pioglitazone: a promising therapy for psoriasis. Br J Dermatol. 2005;152(1):189-91.

19. Cohn G, Valdes G, Capuzzi DM. Pathophysiology and treatment of the dyslipidemia of insulin resistance. Curr Cardiol Rep. 2001;3(5):416-23.

20. Mehnert $\mathrm{H}$. Metformin, the rebirth of a biguanide: mechanism of action and place in the prevention and treatment of insulin resistance. Exp Clin Endocrinol Diabetes. 2001;109 Suppl 2:S259-64

21. Stadtmauer LA, Wong BC, Oehninger S. Should patients with polycystic ovary syndrome be treated with metformin? Benefits of insulin sensitizing drugs in polycystic ovary syndrome-beyond ovulation induction. Hum Reprod. 2002;17(12):3016-26.

22. Van Voorhees AS, Feldman SR, Koo JY, Lebwohl MG, Menter A. The psoriasis and psoriatic arthritis pocket guide: treatment algorithms and management options. National Psoriasis Foundation. Available from: https://www.psoriasis.org/health-care-providers/treating-psoriasis.
23. Misra A, Wasir JS, Pandey RM. An evaluation of candidate definitions of the metabolic syndrome in adult Asian Indians. Diabetes Care. 2005;28(2):398-403.

24. Sharma V, Kaur I, Kumar B. Calcipotriol versus coal tar: a prospective randomized study in stable plaque psoriasis. Int J Dermatol. 2003:42(10):834-8.

25. Bongartz T, Coras B, Vogt T, Scholmerich J, Muller-Ladner U. Treatment of active psoriatic arthritis with the PPARgamma ligand pioglitazone: an openlabel pilot study. Rheumatology (Oxford). 2005;44(1):126-9.

26. Brauchli YB, Jick SS, Curtin F, Meier CR. Association between use of thiazolidinediones or other oral antidiabetics and psoriasis: A population based case-control study. J Am Acad Dermatol. 2008;58(3):421-9.

27. Koca R, Altinyazar HC, Yenidunya S, Tekin NS. Psoriasiform drug eruption associated with metformin hydrochloride: a case report. Dermatol Online J. 2003;9(3):11.

28. Demerjian M, Man MQ, Choi EH, Brown BE, Crumrine D, Chang S, et al. Topical treatment with thiazolidinediones, activators of peroxisome proliferator-activated receptor-gamma, normalizes epidermal homeostasis in a murine hyperproliferative disease model. Exp Dermatol. 2006;15(3):154-60.

29. Bhagavathula N, Nerusu KC, Lal A, Ellis CN, Chittiboyina A, Avery MA, et al. Rosiglitazone inhibits proliferation, motility, and matrix metalloproteinase production in keratinocytes. J Invest Dermatol. 2004;122(1):130-9.

30. Buckingham RE. Thiazolidinediones: Pleiotropic drugs with potent antiinflammatory properties for tissue protection. Hepatol Res. 2005;33(2):167-70.

31. Takagi T, Yamamuro A, Tamita K, Yamabe K, Katayama M, Mizoguchi S, et al. Pioglitazone reduces neointimal tissue proliferation after coronary stent implantation in patients with type 2 diabetes mellitus: an intravascular ultrasound scanning study. Am Heart J. 2003;146(2):E5.

32. Marx N, Wohrle J, Nusser T, Walcher D, Rinker A, Hombach V, et al. Pioglitazone reduces neointima volume after coronary stent implantation: a randomized, placebo-controlled, double-blind trial in nondiabetic patients. Circulation. 2005;112(18):2792-8.

33. Li W, Ma W, Zhong H, Liu W, Sun Q. Metformin inhibits proliferation of human keratinocytes through a mechanism associated with activation of the MAPK signaling pathway. Exp Ther Med. 2014;7(2):389-92.

34. Glossmann H, Reider N. A marriage of two "Methusalem" drugs for the treatment of psoriasis?: Arguments for a pilot trial with metformin as add-on for methotrexate. Dermatoendocrinol. 2013;5(2):252-63.

35. United Kingdom Prospective Diabetes Study (UKPDS). Relative efficacy of randomly allocated diet, sulphonylurea, insulin, or metformin in patients with newly diagnosed non-insulin dependent diabetes followed for three years. BMJ. 1995;310(6972):83-8.

36. UK Prospective Diabetes Study (UKPDS) Group. Effect of intensive blood-glucose control with metformin on complications in overweight patients with type 2 diabetes (UKPDS 34). Lancet. 1998;352(9131) :854-65.

37. Dai $X$, Wang H, Jing Z, Fu P. The effect of a dual combination of noninsulin antidiabetic drugs on lipids: a systematic review and network meta-analysis. Curr Med Res Opin. 2014;30(9):1777-86.

38. Elmadhun NY, Sabe AA, Lassaletta AD, Chu LM, Sellke FW. Metformin mitigates apoptossis in ischemic myocardium. J Surg Res. 2014;192(1):50-8.

39. Miyazaki Y, Mahankali A, Matsuda M, Mahankali S, Hardies J, Cusi K, et al. Effect of pioglitazone on abdominal fat distribution and insulin sensitivity in type 2 diabetic patients. J Clin Endocrinol Metab. 2002; 87(6):2784-91.

40. Yoshii H, Onuma T, Yamazaki T, Watada H, Matsuhisa M, Matsumoto M, et al. Effects of pioglitazone on macrovascular events in patients with type 2 diabetes mellitus at high risk of stroke: the PROFIT-J study. J Atheroscler Thromb. 2014;21(6):563-73.

41. Aronoff S, Rosenblatt S, Braithwaite S, Egan JW, Mathisen AL, Schneider RL. Pioglitazone hydrochloride monotherapy improves glycemic control in the treatment of patients with type 2 diabetes: a 6-month randomized placebo-controlled dose-response study. The Pioglitazone 001 Study Group. Diabetes Care. 2000;23(11):1605-11.

42. Rosenblatt S, Miskin B, Glazer NB, Prince MJ, Robertson KE. The impact of pioglitazone on glycemic control and atherogenic dyslipidemia in patients with type 2 diabetes mellitus. Coron Artery Dis. 2001;12(5):413-23.

43. Kaneko T, Baba S, Toyota T. Dose finding study of AD-4833 in patients with NIDDM on diet therapy alone: double blind comparative study on four dosages. Jpn J Clin Exp Med. 1997;74:1250-77.

44. Kaneko T, Baba S, Toyota T. Clinical evaluation of an insulin-resistance improving agent, AD-4833, in patients with NIDDM on diet therapy alone: a placebo controlled double blind clinical study. Jpn J Clin Exp Med. 1997;74:1491-514. 
45. Chawla S, Kaushik N, Singh NP, Ghosh RK, Saxena A. Effect of addition of either sitagliptin or pioglitazone in patients with uncontrolled type 2 diabetes mellitus on metformin: A randomized controlled trial. J Pharmacol Pharmacother. 2013:4(1):27-32.

46. Kawamori R, Matsuhisa M, Kinoshita J, Mochizuki K, Niwa M, Arisaka T, et al. Pioglitazone enhances splanchnic glucose uptake as well as peripheral glucose uptake in non-insulin-dependent diabetes mellitus. AD-4833 Clamp-OGL Study Group. Diabetes Res Clin Pract. 1998;41(1):35-43.

47. Wallace TM, Levy JC, Matthews DR. An increase in insulin sensitivity and basal beta-cell function in diabetic subjects treated with pioglitazone in a placebo-controlled randomized study. Diabet Med. 2004;21(6):568-76.

48. Herz M, Johns D, Reviriego J, Grossman LD, Godin C, Duran S, et al. A randomized, double-blind, placebo-controlled, clinical trial of the effects of pioglitazone on glycemic control and dyslipidemia in oral antihyperglycemic medication-naive patients with type 2 diabetes mellitus. Clin Ther. 2003;25(4):1074-95.

49. Giles TD, Sander GE. Effects of thiazolidinediones on blood pressure. Curr Hypertens Rep. 2007;9(4):332-7.

50. Neumann A, Weill A, Ricordeau P, Fagot JP, Alla F, Allemand H. Pioglitazone and risk of bladder cancer among diabetic patients in France: a populationbased cohort study. Diabetologia. 2012;55(7):1953-1962.doi:10.1007/s00125012-2538-9.

51. Azoulay L, Yin H, Filion KB, Assayag J, Majdan A, Pollak MN, et al. The use of pioglitazone and the risk of bladder cancer in people with type 2 diabetes: nested case-control study. BMJ. 2012;344:e3645.

52. Lewis JD, Ferrara A, Peng T, Hedderson M, Bilker WB, Quesenberry Jr CP, et al. Risk of bladder cancer among diabetic patients treated with pioglitazone: interim report of a longitudinal cohort study. Diabetes Care. 2011;34(4):91622.

53. TPC Limited. Takeda Announces Completion of the Post-Marketing Commitment to Submit Data to the FDA, the EMA and the PMDA for Pioglitazone Containing Medicines Including ACTOS. 2014. Available from: https://www.takeda.com/news/2014/20140829_6714.html.

54. Chang CH, Lin JW, Wu LC, Lai MS, Chuang LM, Chan KA. Association of thiazolidinediones with liver cancer and colorectal cancer in type 2 diabetes mellitus. Hepatology. 2012;55(5):1462-72.

55. Tseng $\mathrm{CH}$. Pioglitazone and bladder cancer: a population-based study of Taiwanese. Diabetes Care. 2012;35(2):278-80.

56. Lin HC, Hsu YT, Kachingwe BH, Hsu CY, Uang YS, Wang LH. Dose effect of thiazolidinedione on cancer risk in type 2 diabetes mellitus patients: a sixyear population-based cohort study. J Clin Pharm Ther. 2014;39(4):354-60.

\section{Submit your next manuscript to BioMed Central and we will help you at every step:}

- We accept pre-submission inquiries

- Our selector tool helps you to find the most relevant journal

- We provide round the clock customer support

- Convenient online submission

- Thorough peer review

- Inclusion in PubMed and all major indexing services

- Maximum visibility for your research

Submit your manuscript at www.biomedcentral.com/submit

C Biomed Central 